\title{
Plume Behavior in a Confined Tall and Narrow Space -as One of Sub-Models of Plume for an Atrium
} Fire-

\author{
SATOH HIROOMI, ${ }^{a}$ OSAMI SUGAWA, ${ }^{b}$ KITOSHI KURIOKA, ${ }^{a}$ and WATARU TAKAHASHI ${ }^{b}$ \\ a Kajima Technical Institue, Kajima Corp. \\ 2-19-1 Tobitakyu, Chofu-shi, Tokyo 182, Japan \\ ${ }^{\mathrm{b}} \mathrm{Center}$ for Fire Science and Technology. Science University of Tokyo \\ 2641 Yamasaki, Noda, Chiba 278, Japan
}

\begin{abstract}
Experimental study on a flow behavior of flame and plume was carried out using a full scale atrium model and a reduced one having low-inlet and high-outlet openings under natural ventilation condition. Similarities between these spaces were pursued on representative $\Delta T / T$ in the space and on the inflow behavior which is represented by Froude number estimated at the lower opening(s). Interaction between inflow and flame/plume in the confined space was investigated using the reduced model with some variations of inlet opening arrangements. Temperatures and velocities were measured in a flame, plume, and in the confined space to characterize their vertical and horizontal distributions. Observations on visualized door jet(s), flame inclination (direction and angle), and flame height/length were also conducted in the reduced model. Horizontal distributions of temperature and of velocity are well simulated by doubled Gaussians considering central core region and turbulent peripheral region. Decreasing mode of temperature and velocity along the ascending trajectory in of the core parts were similar to those obtained in an open space. Flame length which is affected by direct or indirect door jet(s) showed the similar manner against heat release rate but lower than these in an open space. And dimensionless flame shape was well correlated to the $2 / 3$ power of dimensnsionless heat release rate modified with a Froude number. Overall entrainment into a confined space is proportional to the $2 / 5$ power of dimensnsionless heat release modified by a Grashof number. The confined flame affected with door jet(s) showed the normalized plume radius, b/z, increased about 1.9 times faster than it observed in a free plume in the lower region of the plume.
\end{abstract}

KEYWORDS: confined plume, flame height, doubled Gaussian, door jets, flame inclination

\section{NOTATION LISTS}

A: floor area of the confined space $\left(\mathrm{m}^{2}\right) \quad$ b: half-length of a distribution $(\mathrm{m})$ $A_{W}$ : area of inlet opening $(m) \quad C$ : space factor $(\rightarrow$, defined in [13],

$A_{\text {exh: }}$ area of outlet opening (m) 
$\mathrm{C}_{\mathrm{D}}$ : opening coefficient $(=0.7$ for reduced model, 0.67 for full scale model)

$\mathrm{D}_{\mathrm{o}}$ : characteristic length of floor, $\mathrm{A}^{1 / 2},(\mathrm{~m})$

$\mathrm{D}$ : opening length, $\mathrm{A}_{\mathrm{w}}{ }^{1 / 2},(\mathrm{~m})$

Fr: Froude Number, $u /(\mathrm{gD})^{1 / 2}(\rightarrow$

Gr: Grashof Number $(\rightarrow$

$\mathrm{H}$ : height of the confined space (m)

$\mathrm{H}_{\text {open }}$ : height between lower and higher openings (m)

$j: \mathrm{H}_{\text {open }} / \mathrm{H}(\rightarrow$

$K: \mathrm{A}_{\mathrm{exh}} / \mathrm{A}_{\mathrm{w}}(\rightarrow$

$\mathrm{L}$ : length or height of a flame in a confined space $(\mathrm{m})$

$\mathrm{m}: \mathrm{D} / \mathrm{D}_{\mathrm{o}}(\rightarrow$

$\mathrm{m}_{\mathrm{a}}$ : inflow air mass flux at inlet opening $(\mathrm{kg} / \mathrm{sec})$

$\mathrm{Q}$ : heat release rate $(\mathrm{kW})$

$\mathrm{Q}^{*} \mathrm{~d}$ :dimensionless heat release rate [12],

$$
Q_{d}^{*}=\frac{Q}{\rho_{a} \cdot C p \cdot T_{a} \cdot \sqrt{g} \cdot D^{5 / 2}} \text { * }
$$

$v$ : horizontal door jet velocity $(\mathrm{m} / \mathrm{sec})$

$u$ : velocity along plume trajectory

$v$ : dynamic viscosity $\left(\mathrm{m}^{2} / \mathrm{sec}\right)$

W: width of opening (m)

$\mathrm{Z}$ : height (m)

$\beta$ : thermal expansion $1 / 273(1 / \mathrm{K})$

$\rho_{\mathrm{a}}:$ air density $\left(\mathrm{kg} / \mathrm{m}^{3}\right)$

subseript

o: along the ascending trajectory (almost along the center line)

f: flame

a: ambient

$\mathrm{d}$ : opening for inlet

T: temperature

v: velocity

\section{INTRODUCTION}

In recent several years, the number of buildings having not only a tall and narrow atrium space but also a cubic and a mall-type space has been increasing in Japan. These atrium spaces, of which dimensions, aspect ratio of ceiling height to floor area, $\mathrm{H}^{2} / \mathrm{A}$, are quite different from ones of usual rooms. Especially an atrium of tall and narrow configuration must produce a significant stack effect when a fire source is located in its bottom with openings of entrance (or escape doors) and of exhaustion. Usual plume models, such as a free plume, have been composed based on the experiments carried out in an open space or in a huge space avoiding boundary effect except floor. In these, a stack effect and a wind (door jet from openings) effect to the flame/plume have been underestimated or neglected. McCaffrey[1] and Zukoski et al.[2] suggested the influence of door jet to a flame/plume behavior. Quintiere et al.[3] reported that flames in an enclosure tend to more entrain than idealized plume and the flame inclination is influenced by door jet. Kumar et al.[4] reported the convection flow behavior including door jet and plume in an enclosure based on 3D-field model simulation. Discussions of these papers implied that a strong door jet(s) given by a stack effect may produce significant effects on the flame/plume behavior. And stack effect problems imply also that the present models, such as a free plume model, are not applicable or insufficient for a confined plume. Knowledge of flame behavior has been playing an important role in the fire safety design. Although little systematic accumulation of data has been achieved regarding on the flames influenced by draught in a confined space. In this paper, we intend to describe the flow behavior of flame/plume in an atrium space to establish a sub-model for a confined plume. We tried firstly to find out and establish the similarity between a full scale atrium space and a reduced one on fire behaviors which can evaluate the stack effect and the interaction of door jet(s) to a flame/plume. Secondarily, in order to get deeper understanding on the flow behavior of the confined space, we concentrate on the experimental study on the measurements of door jet and upward flow velocity and temperature using the reduced scale model. 


\section{EXPERIMENTAL PROCEDURE}

\subsection{Atrium Model and A Fire Source}

a) Reduced Model

Main experiments were conducted using a reduced scale atrium model of $1.8 \mathrm{~m} \times 1.8 \mathrm{~m}$ (floor area) $\times 7.2 \mathrm{~m}$ high. One or two low-inlet openings were set at the front wall and two high-outlet openings were set at the top of the back wall, as shown in Figure 1. Each outlet-opening have $22.5 \mathrm{~cm}$ high and $15 \mathrm{~cm}$ wide (to give almost $1 / 50$ of the floor area) with $150 \mathrm{~cm}$ separation between them. The lower edge of the inlet-opening(s) were fixed to floor level having $22.5 \mathrm{~cm}$ high $\times 30 \mathrm{~cm}$ wide as the standard opening area which corresponds to about $1 / 50$ of the floor area. In order to get opening effect on flame/plume behavior, the width of inlet opening centered was changed from $5 \mathrm{~cm}$ to $180 \mathrm{~cm}$ systematically. Five types of arrangements for inletopening(s) were adopted as shown in Figure 4. Front and back walls and the foot region $(90 \mathrm{~cm}$ height) of side walls were finished with $6 \mathrm{~mm}$ thick wired glass enable to observe the flame shape, inclination and direction. A propane gas diffusion burner $(10 \mathrm{~cm} \times 10 \mathrm{~cm}$ square, filled with ceramic beads) was centered at the atrium bottom and which gave $1.5,3,6,12$ and $24 \mathrm{~kW}$ to the space.

\section{b) Full Scale Model}

The full scale atrium model has a simple space of

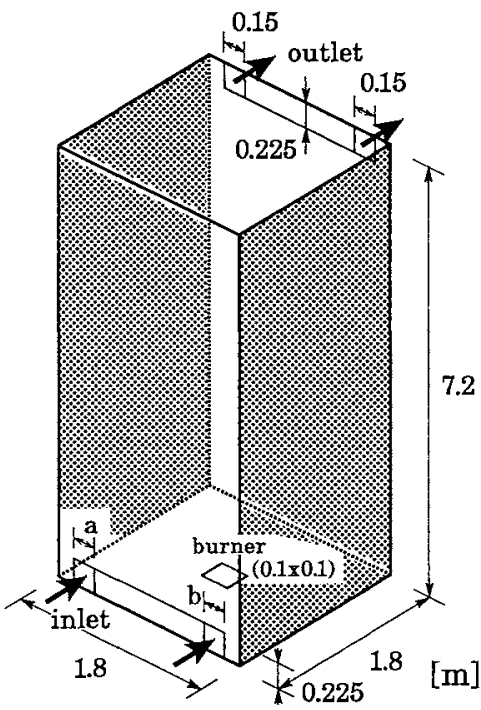

Gypsum plaster board $21 \mathrm{~mm} t$ Wired glass $6 \mathrm{~mm} t$

Figure 1 lllustrated views of the reduced atrium scale model of $1.8 \mathrm{~m} \times 1.8 \mathrm{~m} \mathrm{x}$ $7.2 \mathrm{~m}$. A fire source, propane gas diffusion burner of $10 \mathrm{~cm} \times 10 \mathrm{~cm}$, was set at the center of the floor. $10.2 \mathrm{~m} \times 19.2 \mathrm{~m}$ (floor area) $\times 63 \mathrm{~m}(\mathrm{H})$ with four entrances doors (two of them in the same side were closed) and an exhaustion roof opening at the top. A methanol square pool fire of about $1,2,3$, and $4 \mathrm{~m}^{2}$ giving $83,351,748$, and $1684 \mathrm{~kW}$ (assuming stoichiometric combustion reaction based on regression rate) was located on the bottom level of the space. Temperature, door jet velocity, and ascending velocity in the space were measured with changing the opening arrangements and heat release rates.

\subsection{Measurements and Observations}

\section{a) Temperature and Velocity}

K-type thermocouples are distributed having suitable distances for vertical and lateral directions in flame/plume regions and in the atrium space. To avoid the thermal radiation from a flame to the heads of thermocouples, strips of aluminum foil were set to cover them. Bidirectional tubes [5], five sets on a rake with thermocouples for density calibration, were used in the reduced model and the system was moved up and down to cover the wide range of the plume. At the inlet-openings, two hot wire anemometers (reduced model) and four anemometers (full scale atrium) were used simultaneously to monitor the inflow velocity.

b) Visualization of Door Jet and Flame Inclination

Visualization of door jet(s) from inlet opening(s) was carried out only in the reduced scale 
model utilizing the smoke wire method [6] (which produce white smoke from a wire surface when a wire was heated instantaneously by discharge from electric condensers). The images of door jet(s) visualized, and length and inclination of a flame were recorded by a video system. The recorded images were scaled with references to the three-dimensional standard points established within the model space.

\section{RESULTS and DISCUSSION}

3.1 Similarity between Full Scale and Reduced Scale Atrium Space on Fire Behavior

It is necessary to confirm the similarity between a full scale atrium space and reduced one on the governing factors of fire behavior. We assumed the temperature rise of $\Delta T / T$ in the space and the inflow behavior (which is represented by Froude number) at the lower opening as the characteristic factors to evaluate the similarities for the system. These two factors were evaluated based on mass, heat, and momentum balances with consideration of heat loss to the walls, $Q, A_{\text {exh }} / A_{W}$, $\mathrm{H}^{2} / \mathrm{A}$, and also applying the Froude modeling. Figure 2 shows the relation between the $\mathrm{Fr}_{\mathrm{d}}$ and modified dimensionless heat release rate of $C^{1 / 2} \cdot Q^{*}{ }_{d}^{1 / 3}$ obtained from the experiments in the full scale atrium space and the reduced one. The detailed derivation of $\mathrm{C}$ is not discussed here, as it is defined by $C=\left(\mathrm{J} /\left(\mathrm{C}_{\mathbf{D}} \cdot \mathbf{m}\right)\right)^{2 / 3}\left(2 \mathrm{~K}^{2} /\left(1+\mathrm{K}^{2}\right)\right)^{2 / 3}\left(\mathrm{H}^{2} / \mathbf{A}\right)^{1 / 3}$ [12] including the opening factor of $\mathbf{K}=\mathrm{A}_{\mathrm{exh}} / \mathrm{A}_{\mathbf{W}}$. Plots in Figure 2 clustered into a line and this implies the similarity is assured between the full scale and reduced atrium spaces regarding on the inflow behavior. We assumed adiabatic condition to the system as a first analysis so that the clustered line of plots in Figure 2 shows little lower than the ideal line showed by a broken line. Figure 3 shows the representative temperature rise, $\Delta \mathrm{T} / \mathrm{T}$, obtained from the both atrium spaces as a function of $Q^{*} \mathbf{d}^{2 / 3} /\left(C_{D} \cdot C^{1 / 2}\right)[12]$, where

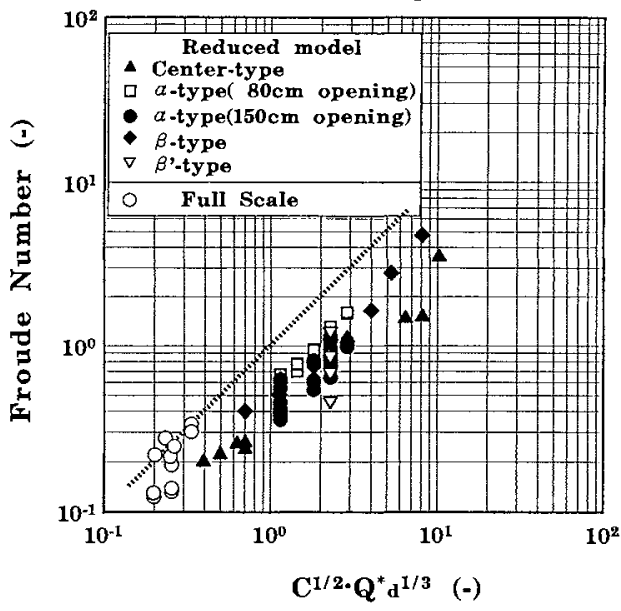

Figure 2 Froude number evaluated at the inlet opening as a function of dimensionless modified heat release rate obtained from a full scale model atrium and a reduced one.

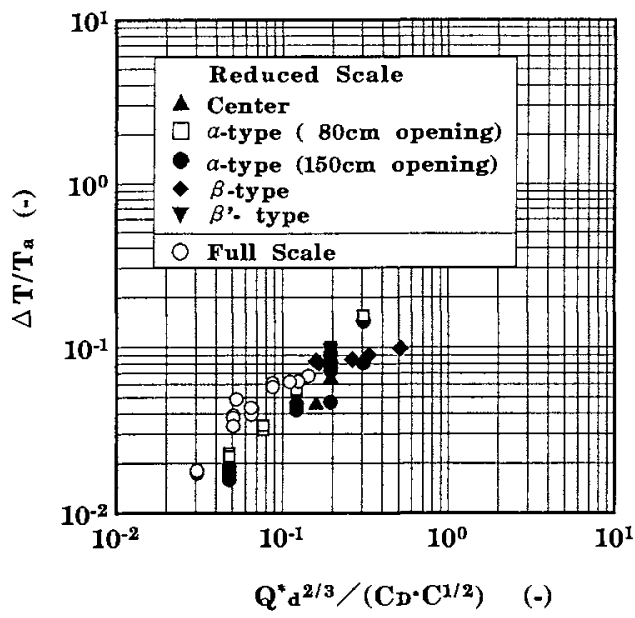

Figure 3 Dimensionless temperature rise $\Delta T / T$ in the atrium space as a function of dimensionless modified heat release rate obtained from a full scale model atrium and a reduced one. 
$\Delta \mathrm{T}$ was estimated from almost the center of the plume of which diameter expanded to the inner wall of the atrium showing almost plug flow. Figure 3 indicate the similarity between the full scale and the reduced atrium models regarding on $\Delta T / T$ if we accept the modification factor of $C$.

\subsection{Deformation of a Flame in Reduced Model}

(a) Direction of Inclination

Outside air induced through the inlet-opening(s) formed door jets. A conceptual illustration of interference draught-zones with a flame for each opening arrangement are also shown by an arrow. The size of the draughts and the extent of their interference with the flame depended on both location and widths of openings. The smoke-wire method was applied for the visualization of the door jets velocity profiles in the reduced model, and of which typical images obtained from two independent experiments for the cases of centered opening, symmetrical two openings ( $\alpha-$ type), and off-centered opening ( $\gamma$-type) are shown in Figure $5-(a) \sim(c)$. Velocity distributions of the jets were generally flat. Jets from two openings in proximity to one another merged and could be regarded as a single jet. The width of the door jet expanded laterally showing about $10 \sim 15$ degree. When $\alpha$-type opening was set with a fixed-separation, as shown in Figure 4-(b), flame inclined inward while in the merged draught zone but toward the openings at other times. When the separation of openings was set at $80 \mathrm{~cm}$ in $\alpha$-type, the flame stood almost vertically. Here the width. and location of the opening determined whether the flame was in the mergeddraught zone or the convection zone of returning jet from inward, and the direction of flame inclination was reversed accordingly. In the case of two openings of unequal width were provided, shown in Figure 4-(d), and the flame was not contained in the draught zone flame inclined toward the wider opening under the more powerful influence of draughts from it. Figure

\section{Inlet Opening Arrangements}

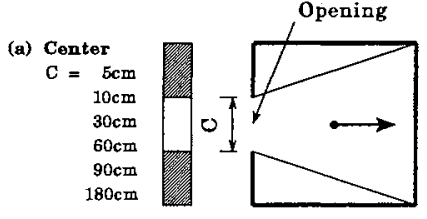
(b) a-type
$a=10 \mathrm{~cm}$
$80 \mathrm{~cm}$
$160 \mathrm{~cm}$

$20 \mathrm{~cm}$

$40 \mathrm{~cm}$

$60 \mathrm{~cm}$
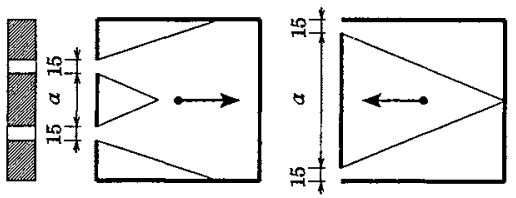

(c) $\beta$-type
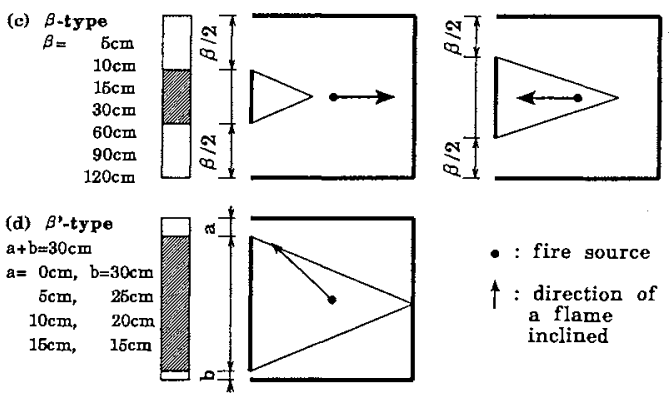

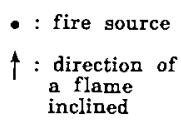

(e) 7-typo

$\gamma=5 \mathrm{~cm}$

$15 \mathrm{~cm}$

$60 \mathrm{~cm}$

$90 \mathrm{~cm}$

$120 \mathrm{~cm}$

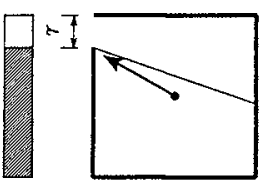

Figure 4 Plan views of the location and arrangement of inlet-openings of the reduced model. A conceptual illustration of the expansions of door jet with their interference with a flame for each arrangement of openings are also shown. Arrows mean the representative inclination direction of a confined flame for each opening arrangement. 
4-(e) illustrates the case in which a single opening was made at a corner, the direction of flame inclination appeared to be determined by the peripheral velocity gradient of the door jets. When a flame was stricken directly by door jet from the opening centered, the linear functional relationship between flame inclination angle and door width was obtained as shown in Figure 6. This relation appeared to be coincide with those reported by Quintiere et al. [3] but not with ones by Raj et al. [7]. It is apparent, however, as shown in Figures 6, that the above correlation does not appropriate for the flame influenced by indirect door jets strike showing complex behavior depend on the openings arrangements.

We observed that flame length in a confined space showed shorter than one obtained from a free space. For example, a $12 \mathrm{~kW}$ fire showed about $60 \pm 10 \mathrm{~cm}$ and of which corresponding length was of $80 \pm 10 \mathrm{~cm}$. Let us assume the whole flame was uniformly subjected to or influenced with door jets of $v$, the representative ascending velocity of flame/plume $u$, the length or height of a flame $\mathrm{L}_{\mathrm{f}}$, then the bulk heat flux passes through the inclined flame is given by $\mathrm{Q} \propto \rho \mathrm{Cp} u \Delta \mathrm{T}(v / u) \mathrm{D}^{2}$ and this can be rewritten as (1) followed by [8],

$$
\mathrm{L}_{\mathrm{f}} / \mathrm{D} \propto\left(\mathrm{Q}^{*}{ }_{\mathrm{d}} / \mathrm{Fr}\right)^{\mathrm{n}} \text {. }
$$

In order to obtain power correlation between $\mathrm{L}_{f} / \mathrm{D}$ and $\mathrm{Q}^{*}{ }_{\mathrm{d}} / \mathrm{Fr}$, we plotted these dimensionless numbers obtained experimentally in the opening arrangements of centeredtype, $\alpha$-type, and $\beta$-type openings. Estimating the coefficient and gradient from Figure 7 , we obtained equation (2),

$$
\mathrm{L}_{\mathrm{f}} / \mathrm{D}=\mathrm{c}\left(\mathrm{Q}^{*} \mathrm{~d} / \mathrm{Fr}\right)^{2 / 3}, \mathrm{c}=1.8 \sim 2.0 \text {. }
$$

The equation (2) is similar to the power correlation obtained for an open square fire if we accept the $\mathrm{Q}^{*}{ }_{\mathrm{d}} / \mathrm{Fr}$ instead of $\mathrm{Q}^{*}{ }_{\mathrm{d}}$. The coefficient is about $1 / 2$ smaller than that of an open fire. Equation (2) is applicable to the estimation of a confined flame height/length with various opening arrangements including direct and indirect striking of door jet(s) to a flame.

\subsection{Temperature and Velocity along the ascending trajectory}

\section{(a) Temperature}

Figure $8-a$ shows the temperature distribution along the ascending trajectory (or along almost the center line) normalized by $\mathrm{Q}^{2 / 5}$ in the cases of the opening centered with width of $5 \mathrm{~cm}, 30 \mathrm{~cm}$, and $120 \mathrm{~cm}$. This figure shows that temperatures are lower than those of open field as a result of entrainment induced by direct door jet striking. The temperature decreasing mode along the ascending trajectory is similar mode which were expected from a free plume from a square fire.

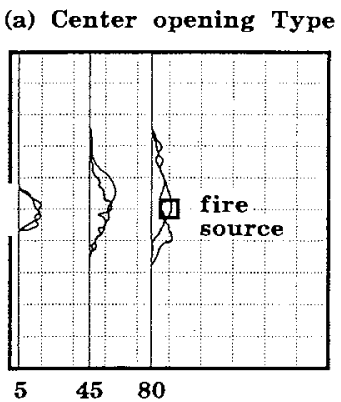

(b) a-opening Type

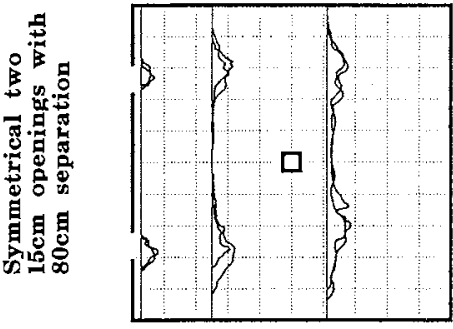

(c) $\gamma$-opening Type

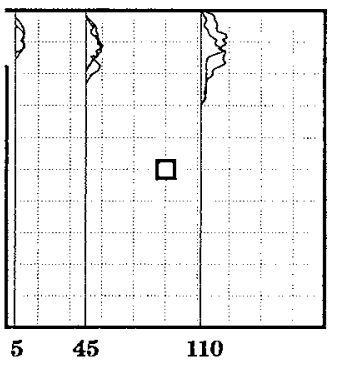

Figure 5 Visualized velocity profiles (independent two experimental results are superimposed) of door jet(s) using a $12 \mathrm{~kW}$ fire centered, (a) centered-opening, (b) $\beta$-type, and (c) $\gamma$-type. 
However, Figure 8-b shows those temperatures obtained from the $\alpha$-type opening with the separation of $80 \mathrm{~cm}$, temperature of the upper plume region showed smaller descending mode from $z^{-5 / 3}$ resulted from the limiting of air entrainment which was blocked by surrounding walls. The height where the temperature appeared to be sustained or to less descending from the mode of $z^{-5 / 3}$ showed almost the same height or scarcely dependent on the heat release rate in the present cases. This suggests that the periphery of the turbulent plume touch to walls at the height of about $1.5 \mathrm{~m}$. And this indicated the apparent ratio of plume radius to height, $b / z$, in a confined atrium space increased about 1.9 times faster than it of a free plume.

\section{(b) Plume Velocity}

In order to compare the characteristic of plume velocity along the ascending trajectory with the one observed in a free plume, we choose the velocity data of the $\alpha$-type opening with a separation of $80 \mathrm{~cm}$ applied a

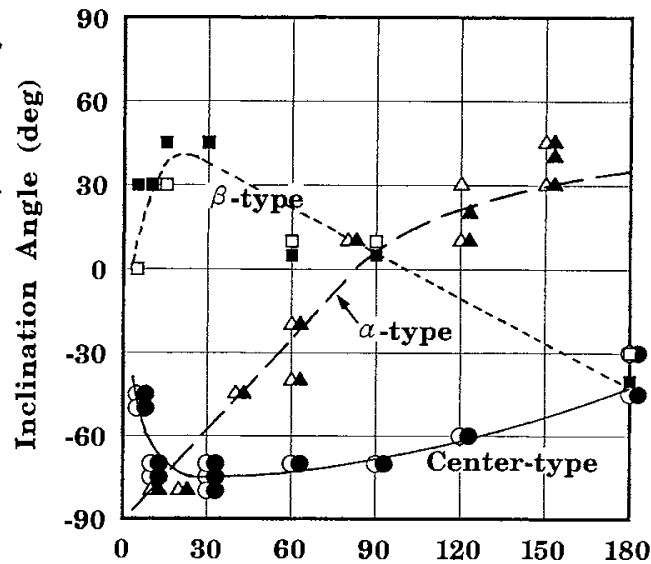

Opening Arrangement (cm): $\beta, \gamma$-type Opening width (cm): $\alpha$-type

Figure 6 Angle of a flame inclined as a function of width of inlet-opening(s) for centered-type, $\alpha$-type, and $\gamma$-type. Open mark is $4 \mathrm{~min}$ data and block is $6 \mathrm{~min}$ data, respectively. $12 \mathrm{~kW}$ fire. In this case, door jets stroke indirectly to the flame and which made the flame almost vertically standing. Upward velocity along the ascending trajectory showed roughly two modes of $\mathrm{Z}^{0}$ and of $\mathrm{Z}^{-1 / 3}$, as shown in Figure 9. It was not clearly observed that the increasing mode of $Z^{1 / 2}$ for the flame region. Even in the flame region, upward velocity along the center line showed $\mathrm{Z}^{0}$ mode and was continued into the intermittent region. The door jets velocity (order of $\mathrm{m} / \mathrm{sec}$ ) was $10 \sim 100$ times faster than usual entrainment velocity (order of $\mathrm{cm} / \mathrm{sec}$ ) so that the confined flame was affected by door jet striking resulting in the well mixed flame with air entered. In the upper region of the plume ranging about $6 \pm 1 \leq \mathrm{Z} / \mathrm{b} \leq$ about 42 , upward velocity showed $\mathrm{Z}^{-1 / 3}$ decreasing mode. And this mode was similar decreasing mode to the one obtained in an open plume from a square fire.

\subsection{Horizontal Distribution}

\section{(a) Temperature}

Different from a free plume, a plume in an atrium space was affected by the presence of solid boundaries and resulted in a confined plume showing less entrainments and contact with walls in the upper part of plume. An interaction between hot gas plume and contact inner wall surfaces resulted in the strongly buoyant central core region and the peripheral turbulent region similar to the wall jet $[9,10]$. In order to include these two properties into the same horizontal distribution, we simulate the horizontal distribution of temperature by doubled Gaussian composed of two overlapped Gaussians for these two regions as expressed, 


\section{$\Delta \mathrm{T}(\mathrm{r}, \mathrm{z})$}

$$
\begin{aligned}
= & \Delta \mathrm{T}_{\mathbf{0}}(\mathbf{z})\left\{\phi_{\mathrm{T}} \cdot \exp \left(-\mathbf{r}^{2} / \mathbf{b}_{\mathrm{T} 1}^{2}\right) .\right. \\
& \left.+\left(1-\phi_{\mathrm{T}}\right) \cdot \exp \left(-\mathbf{r}^{2} / \mathbf{b}_{\mathrm{T} 2}^{2}\right)\right\}
\end{aligned}
$$

where $\phi_{\mathrm{T}}$ the partitioning factor between core and peripheral parts, and $b_{\mathrm{T} 1}$ and $b_{\mathrm{T} 2}$ are the half-width for those regions, respectively. $\Delta \mathrm{To}$ showed similar decreasing mode with that of a free plume. The comparison, as shown in Figure 10, between the simulated temperature by doubled Gaussian and and those of obtained experimentally shows that the doubled Gaussian profiles is useful for the estimation on the horizontal temperature distribution in a confined plume. Table 1 shows the examples of characteristic values of $\mathrm{b}_{\mathrm{T} 1}, \mathrm{~b}_{\mathrm{T} 2}$, and $\phi_{\mathrm{T}}$ for a $12 \mathrm{~kW}$ fire, and these numbers are useful for the reduced atrium model space covering the $1.5 \mathrm{~kW}$ to $24 \mathrm{~kW}$ fires. This suggests that the plume shape produced by different fire sizes were the almost the same with one another, and were controlled mainly not by fire size but by the configuration of the confined space.

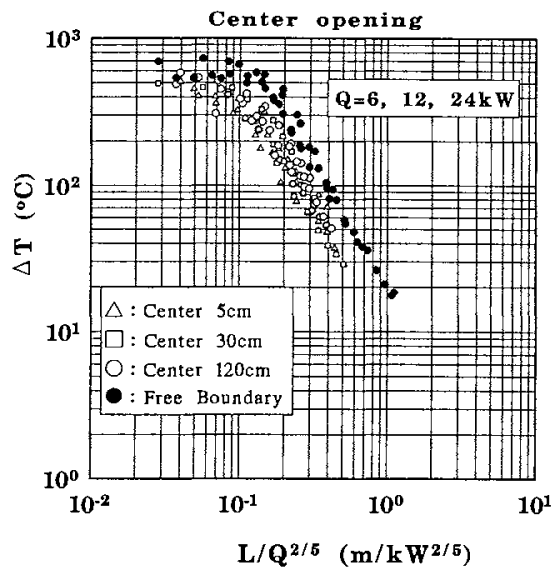

Figure 8-(a) Excess temperature distribution for vertical direction along the ascending trajectory (almost along the center line) with the opening arrangement of centered. Vertical height are normalized by $2 / 5$ powered of heat release rates.

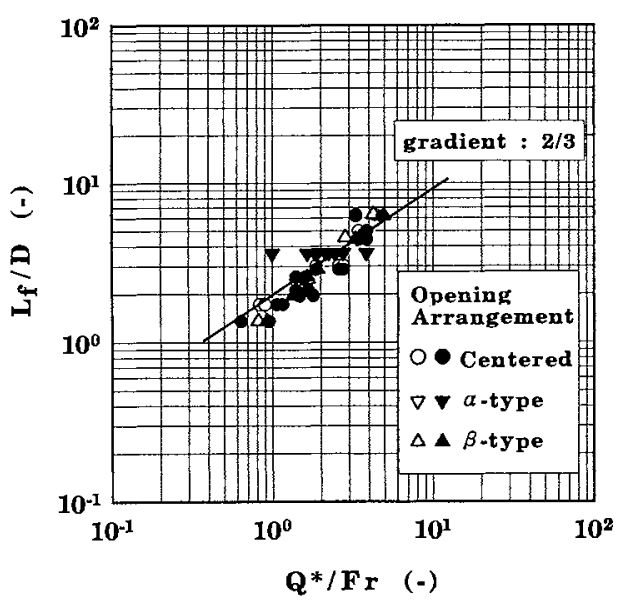

Figure 7 Dimensionless flame length, $\mathrm{L}_{\mathrm{f}} \mathrm{D}$, as a function of dimensionless heat release rate, $Q^{*}$, modified by Froude number Fr.

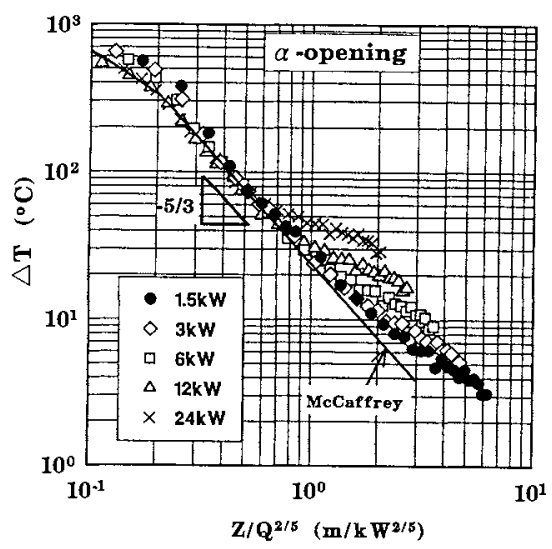

Figure 8-(b) Excess temperature distribution for vertical direction along the ascending trajectory (almost along the center line) with the two symmetrical openings ( $\beta$-type). Vertical height are normalized by $2 / 5$ powered of heat release rates. 
(b) Plume Velocity

The horizontal distribution of plume velocity in the reduced model showed upward and downward in the same horizontal plane in the region of about $\mathrm{Z} / \mathrm{b}=7$ (almost flame tip height) to $Z / b=38 \sim 46$. Upward velocity alone was observed in the two regions: under the region of about $\mathrm{Z} / \mathrm{b}=7$ and upper of about $\mathrm{Z} / \mathrm{b}=42$ (between the height of $\mathrm{Z}=3.8 \mathrm{~m}$ and $4.6 \mathrm{~m}$ in the present case) except the boundary layer close to the wall. Upward velocity appeared all heights in the central core region along the ascending trajectory, and downward velocity was observed in peripheral region. If we adopt the doubled Gaussian profile for the velocity profile taking central core region of upward and turbulent downward velocity of peripheral region, the velocity profile in a confined plume was successfully simulated by equation (4),

$$
\begin{aligned}
& v(r, z)= \\
& \nabla_{0}(z)\left\{\phi_{v} \cdot \exp \left(-r^{2} / b_{v 1}^{2}\right)\right. \\
& \left.+\left(1-\phi_{v}\right) \cdot\left(-r^{2} / b_{v 2}^{2}\right)\right\}
\end{aligned}
$$

Taking negative number for $\phi_{\mathrm{v}}$, upward and downward velocity in the same horizontal plane can be expressed by the equation (4), and are compared with the measured data in Figure 10. Simulation can not be done perfectly as done in temperature due to difficulty of measurements in turbulent flow having upward and downward in the confined space. Table 1 shows the typical characteristic values of the half-width of the core region, $b_{\mathrm{v} 1}$, and half-width of the turbulent peripheral region, $b_{\mathrm{v} 2}$, with the proportioning factor $\phi_{\mathrm{v}}$. The width of $b_{\mathrm{v} 1}$ was almost same to ones of temperature profile and increased with height in the flame region but almost same length in upper the flame region. This suggests that the core region of the confined plume is narrow and is almost maintained the same size for vertical

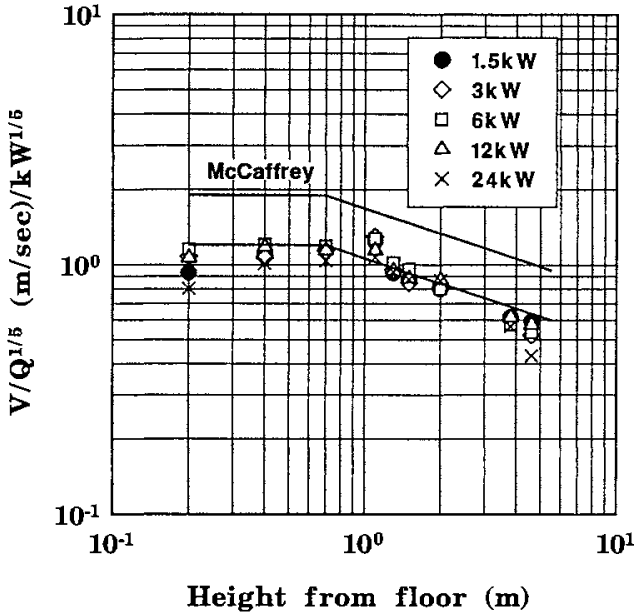

Figure 9 Upward velocity normalized by $Q^{1 / 3}$ versus height along the ascending trajectory (almost the center line) in an atrium model space.

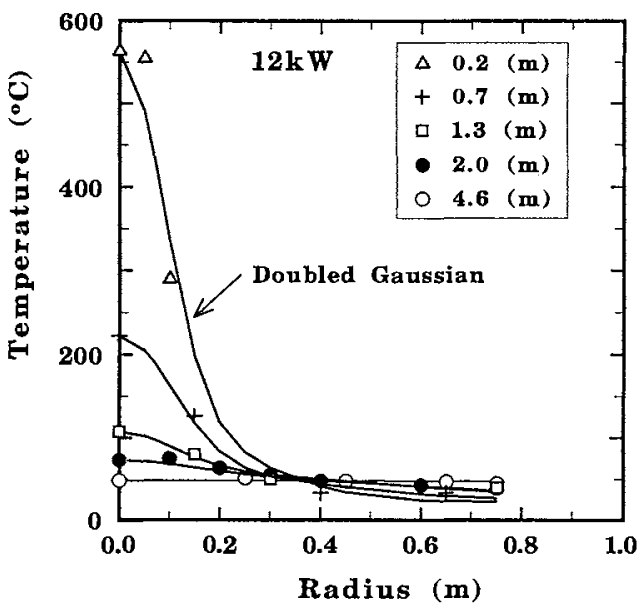

Figure 10 Horizontal distribution of excess temperature simulated by the double Gaussian and with comparisons of experimental data measured. 
direction where the almost plug flow was established above the height of $\mathrm{Z} / \mathrm{b}=42$ in the present confined space.

\subsection{Entrainment into the Confined Space}

For turbulent flow along a wall, it was reported that the mass flux is proportional to the $2 / 5$ power of a Grashof number [10]. If we assume $\Delta \mathrm{T}$ correlates directly to the heat release rate, we could take a modified Grashof number by $\mathbf{Q}_{\mathbf{d}}^{*} \mathbf{g} \cdot \boldsymbol{\beta} \cdot \Delta \mathbf{T} \cdot \mathbf{H} \cdot \mathbf{A} / \boldsymbol{v}^{2}$. In the present case, space factors of $\mathrm{H}$ and $A$, and physical factors of $g, \beta$, and $v$ were assumed as constant so that coupled dimensionless number of $\mathrm{Gr}$ and $Q^{*}{ }_{d}$ is represented only by $Q^{*}{ }_{d}$. This implies the induced air mass flow is proportional to the $2 / 5$ power of $\mathrm{Q}$. Figure 12 shows the inflow velocity at inlet-openings as a function of $\mathrm{Q}^{*}{ }_{d}$ with various opening arrangements. This shows clearly the induced velocity, in other word inflow mass, is proportional to $\mathrm{Q}^{*} \mathrm{~d}^{2 / 5}$. Overall entrainments into the space was not depend on the opening arrangements but was strongly depend on $\mathrm{Q}$ with considering the space factor. Using the doubled Gaussian profiles of temperature and velocity referencing with the experimentally obtained data, upward mass fluxes at various heights in the confined space were estimated for $\alpha$-type opening for $1.5 \mathrm{~kW}-24 \mathrm{~kW}$ fires. Entrained air mass flux, $\mathrm{m}_{\mathrm{a}}$, into the confined space was balanced with the upward mass flux when the flow ascended to the height between $\mathrm{Z} / \mathrm{b}=7$ to 10. Applying the equation by Zukoski et al. [2], it can be estimated that a $12 \mathrm{~kW}$ diffusion fire in a free space can transport about $0.4 \mathrm{~kg} / \mathrm{sec}$ mass flux at $\mathrm{Z}=0.7 \mathrm{~m}$ and about $0.86 \mathrm{~kg} / \mathrm{sec}$ at $\mathrm{Z}=1.1 \mathrm{~m}$. In the present confined plume from a $12 \mathrm{~kW}$ fire,

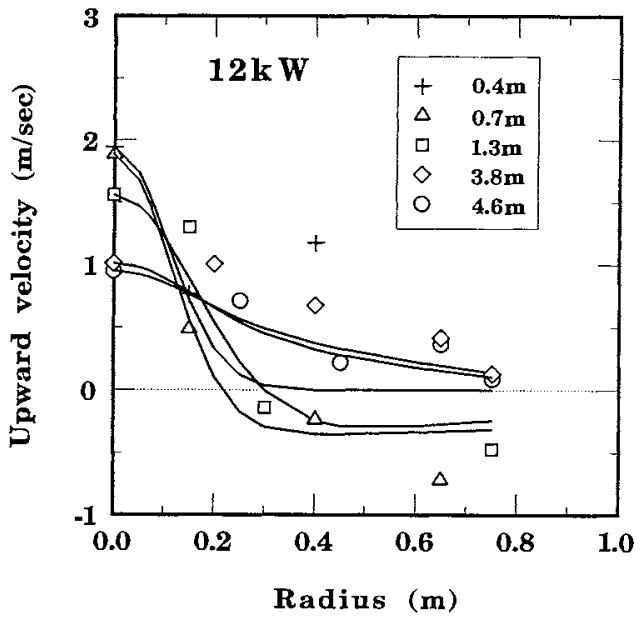

Figure 11 Horizontal distribution of velocity showing upward core region and downward peripheral region. Line shows simulated velocity based on double Gaussian compared with experimental data.

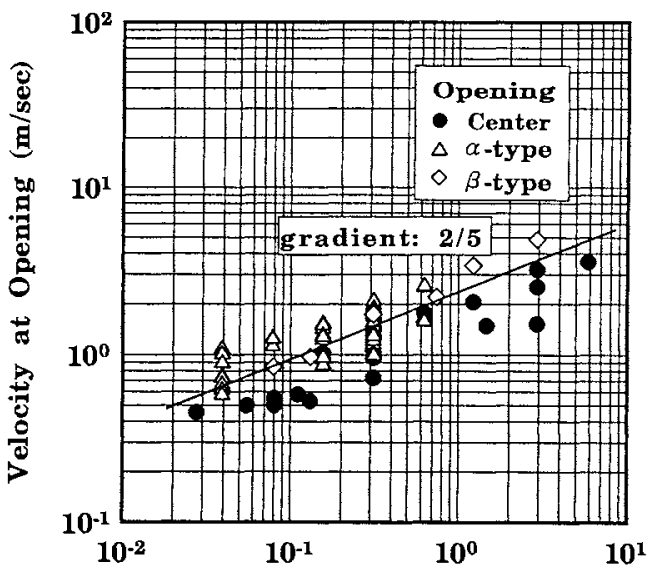

Dimensionless heat release rate $(-)$

Figure 12 Induced opening velocity with the various opening arrangements are plotted against dimensionless heat release rate as a modified Grashof number. 
however, upward gas mass flux transported at these heights were estimated as $0.08 \mathrm{~kg} / \mathrm{sec}$ and $0.12 \mathrm{~kg} / \mathrm{sec}$. A single room fire with a door opening have been reported $[1-3,9]$ showed the entrainment is 2 or 3 times higher than the results predicted by a free plume. In the present test results did not agree with this regarding on the over-all entrainment. Entrainment through the inlet-opening is supposed to be governed by heat flux of a fire (in other words by stack effect) with the affection of opening area and space configuration. This results and Figure 12 propose that Froude number at the opening correlate quantitatively with $\mathrm{Q}^{*}{ }_{\mathrm{d}}$ modified with $\mathrm{H}^{2} / \mathrm{A}$, and $\mathrm{A}_{\mathrm{W}} / \mathrm{A}_{\mathrm{exh}}$.

Table 1 Characteristic Values of Distribution for $12 \mathrm{~kW}$ in Reduced Model

\begin{tabular}{|c|lllllllll|}
\hline Temperature & $0.2 \mathrm{~m}$ & $0.4 \mathrm{~m}$ & $0.7 \mathrm{~m}$ & $1.1 \mathrm{~m}$ & $1.3 \mathrm{~m}$ & $1.5 \mathrm{~m}$ & $2.0 \mathrm{~m}$ & $3.8 \mathrm{~m}$ & $4.6 \mathrm{~m}$ \\
\hline $\mathbf{b}_{\mathbf{T} 1}$ & 0.12 & 0.12 & 0.15 & 0.17 & 0.15 & 0.20 & 0.22 & 0.22 & 0.22 \\
$\mathbf{b}_{\mathbf{T} 2}$ & 0.3 & 0.35 & 0.5 & 0.6 & 0.7 & 0.78 & 0.8 & 2 & 2 \\
$\phi_{\mathrm{T}}$ & 0.2 & 0.2 & 0.2 & 0.2 & 0.45 & 0.6 & 0.65 & 1 & 1 \\
\hline Velocity & & & & & & & & & \\
$\mathbf{b}_{\mathbf{v} 1}$ & 0.08 & 0.15 & 0.16 & 0.20 & 0.23 & 0.22 & 0.22 & 0.22 & 0.22 \\
$\mathbf{b}_{\mathbf{v} 2}$ & - & - & 1.8 & 1.5 & 1.1 & 0.75 & 0.52 & 0.62 & 0.65 \\
$\phi_{\mathbf{v}}$ & 0 & 0 & -0.2 & -0.3 & -0.25 & 0.01 & 0.35 & 0.45 & 0.55 \\
\hline
\end{tabular}

\section{SUMMARY}

Similarities were confirmed experimentally between a full scale atrium model and a reduced one regarding on the dimensionless temperature rise $\Delta T / T$ in the space and on the inflow behavior presented by Froude number. Assured model on heat loss to the atrium walls must be necessary to estimate temperature rise in the space.

Flame was affected by door jets and resulted in inclination and shrinking of flame height/ length but expansion of its width. When a flame was affected by direct door jet from a centered opening, flame inclination phenomenon is similar to a plume in an across wind.

Dimensionless flame height, $\mathrm{L}_{\mathrm{f}} / \mathrm{B}$, is correlated with the $2 / 3$ power of $\mathrm{Q}^{*}{ }_{\mathrm{d}}$ modified by a $\mathrm{Fr}$ for various opening arrangements. And this power correlation is similar to the one obtained in a free space although it showed a smaller coefficient.

The width and location of the openings determined whether the merged-draught zone or the convection zone for a flame, and it determined the direction of flame inclination accordingly. Horizontal distribution of temperature and velocity in a confined space were expressed successfully by the doubled Gaussian. Over-all entrainment into the confined space, implying the stack effect, is supposed to be governed by coupled factor of $\mathrm{Gr}$ and $\mathrm{Q}^{*}{ }_{\mathrm{d}}$ for the natural convection condition.

\section{ACKNOWLEDGMENT}

The authors would like to sincere thanks to Mr. Arai and Mr. Kuwana of the Kajima Technical Research Institute, for their help of the experiments. 


\section{REFERENCES}

1) McCaffrey, B.J. "Purely buoyant diffusion flames - Some experimental results", NBSIR 791910, National Bureau of Standards (1979)

2) Zukoski, E. E., Kubota, T., and Cetegen, G., "Entrainment in fire plumes", Cal. Inst. Tech. Report, DOC Grant G-9014 (1980)

3) Quintiere, J. G., Rinkinen, W. J., and Jones, W. W. "The effect of Room Openings on Fire Plume Entrainment", Combustion Science and Technology, vol.26, pp.193-201, (1981)

4) Kumar, S., Gupta, A. K., and G. Cox., "Effects of Thermal Radiation on the Fluid Dynamics of Compartment Fires", Proc. of The Third Intr. Symp. on Fire Safety Science, pp.345-354, Edit. G.Cox and B. Langford, Elsevier Appl. Science. Edinburgh, (1991)

5) Newman,J.S., and Croce, P.A. Serial No. 21011.4 Factory Mutual Research Corp., Norwood (1985)

6) Handa, T., and Sugawa, O., "Characterization of Flow Behavior of Hot Fire Products in a Concrete Full-Scale Corridor", Journal of Fire Science and Technology, vol.1, No.1 (1981)

7) Raj, P. P. K., Moussa, A. N., and Aravamudau, K., "Experiments involving pool and vapor fires from spills of liquefied natural gas on water", prepared for U. S. Dept. of Transportation U.S. Coast Guard, Report No.CG-D-55-79

8) Sugawa, O., Sato, H. and Oka, Y., "Flame Height from Rectangular Fire Sources Considering Mixing Factor", Proc. of The Third Intr. Symp. on Fire Safety Science, pp.435-444, Edit. G. Cox and B. Langford, Elsevier Appl. Sci., Edinburgh, (1991)

9) McCaffrey, B. J. and Rockett, J. A. "Static pressure measurements of enclosure fires", Journal of Research, NBS,82, (2), (1977)

10) Jaluria, Y., "Natural Convection Wall Flows", Section1/Chapter 7, The SFPE Handbok of Fire Protection Engineering, First Edtion, NFPA and SFPA

11) Zukoski, E. E., Kubota, T., and Cetegen, G., "Entrainment in Fire Plumes" Fire Safety Journal, vol.3, pp.107-121 (1980/81)

12) Satoh, H., Sugawa, O., and Kurioka, H., "Modeling on Temperature and Ventilation for Fire in a Tall and Narrow Atrium", submit to the J. Arch. Plann. and Env. Eng., Architecture Institute of Japan, (1994) 